\title{
Influence of social-economic institutions on innovative environment development: Russian case study
}

\author{
Natalia Chistyakova ${ }^{1}$, Tatiana Gromova ${ }^{1}$, Michail Soloviev ${ }^{1}$, Anastasia Braychenko $^{1}$ \\ ${ }^{1}$ Tomsk Polytechnic University, 634050 Lenin Avenue, 30, Tomsk, Russia
}

\begin{abstract}
One of the important questions for innovative environment development is social-economic institutions, which help to decrease transaction cost and risks in small and medium size enterprises (SMEs). Basic institutional framework is represented by a set of specific institutions, which form the innovation environment of the region and have an impact on the activities of the innovation system actors. The proposed set of institutions is divided into two groups: those institutions that directly affect the development of innovative environment and institutions, which influence is indirect, but nevertheless important. The result of analysis of institutions development of Tomsk region and five more innovation-oriented areas of the Russian Federation is given in the article.
\end{abstract}

\section{Introduction}

For the first time the term "institution" appeared in the works of T. Hobbes in the XVII century, 'the conclusion of the social contract between the people who live in a society without a state, and is applied in the pursuit of profit damage to each other" (Hobbs, 1798) [1]. This category was also analysed by the representatives of classical and neoclassical economic theory Adam Smith, David Hume [2], and H. Spencer [3], meaning the 'institutions' specific mechanism for regulating social relations. Durkheim [4] believed that "institutions are any kind of thoughts, actions and feelings that limit individuals". In [5] a detailed study of the category of "institution" is carried out, in which you can distinguish the following stages of its evolution:

1. Researches of the "old" and "new" German schools (K. Savigny in. Roscher, H. Puchta, G. Schmoller [6], A. Wagner [7]) and of the English (US Canning, Ashley B.) historical school created several definitions of "institution". Firstly, the institutions are investigated as components of complex and interrelated "subsystems" of society; secondly, it acknowledged purposeful "behavior" of institutions aimed at achieving social progress.

2. There are works of the representatives of the school of "old" institutionalism (Veblen, W. Hamilton, C. Ayres, J. Commons). They were the first who gave a detailed definition of economic institutions. Veblen [8] considered the "institution" as "regulating social relations and establishing social rules and conventions including the language of communication, money, law, the system of weights and measures, as well as

\footnotetext{
a Corresponding author: chistyakovan@yahoo.com
}

companies (and other types of organizations)." J. Commons [9] described "institution" as collective action of individual controlling activities.

3. Researchers of new institutionalism (neoinstitutionalism) are theorists R.Kouz, O. Williamson, D. North. One of the fathers of a new institutionalism, D. North [10], considered the category of "institution" as:

- a rule, mechanisms for their implementation, and norms of behavior that structured repeated interactions between people;

- a rule of the game in society, supplemented by the mechanism of coercion to its execution.

While Oliver Williamson [11] suggested understanding the institute as a "structure, aimed at minimizing transaction costs."

Some researchers considered "institutions" as the mechanisms leading to equilibrium. For example, A. Shotter [12] considered institutions as a "balance in the standard coordination game. For us, the institutions are the properties of the equilibrium state of the game, not the properties of the game. "Parallel to this, D. Knight [13] argued that "social institutions are not outcomes of the efforts aimed at limiting the social actors in the collective purposes, but the product of a separate effort of an actor to limit the actions of other actors with which he/she interacts."

Representatives of the neoinstitutionalism school expanded the boundaries of the category "institution", offering to consider this concept in the context of formal and non-formal rules, regulations, customs, traditions, as well as mechanisms of enforcement, set both outside and inside and arising as a result of interaction of subjects. 
Thus, analyzing the authors' work of in this paper, it is proposed to define institution as an innovative element of the environment, including a set of formalized and non-formalized rules and regulations arising as a mechanism of social interaction, as well as restrictions on its regulation, changing in the process of evolution and forming the necessary conditions for economy development.

For a more detailed study of the influence of institutions on the development of the innovative SMEs, it is necessary, first of all, to formulate a list of specific institutional components. It helps to develop a set of indicators, evaluating the adequacy and development of an institution and propose a set of measures to develop the missing institutional characteristics. Analysis of literature has revealed a number of institutions classifications. Matveenko [14] identifies the following types of institutions peculiar to Russia in the transition period: 1) property rights and legal institutions, such as the judicial practice; land legislation, patent law; 2) political institutions, such as forms of democracy, political freedoms; 3) financial institutions: the organization of a banking system, such as one the form of venture capital; 4) formal and informal institutions of labor, such as labor legislation, the possibility of secondary and informal employment, collective loyalty to the company; 5) the institutions of the shadow economy, such as tax evasion schemes. In addition, he notes that schematically the relationship of institutions in economy can be represented as a triangle with the following vertices: 1) political institutions and political power, 2) economic institutions and economic policies, 3) economic performance.

This set of represented institutions, in our opinion, is not full enough, and does not allow exploring innovative environment in the region, as there are no such significant institutional components as the Institute of Trust (authorities, state, etc..), the Institute of Informal Relations, etc. Considering development of institutions directly related to innovation, authors Kolmakov, Shindina [15] noted the necessity of development of the institution and the economic regulation of the processes of activation of innovative entrepreneurial activity involving the several factors. These factors are 1) creation of a flexible legal system; 2) development of the institute of public-private partnership aimed at improving the mechanisms for the development and regulation of the national customs and mentality; 3) forming the institute of innovative infrastructure development aimed at creating the conditions for selfdevelopment of territorial economic systems with the creation of large industrial entities interested in the growth and development of the enterprise sphere, 4) developing $R \& D$ centers and educational institutions, consisting in the creation of infrastructure regulation tools for the redistribution of know-how within the country and within the world community.

This approach is certainly justified in terms of improving innovative SMEs activity, but in terms of the absence of changes in the functioning of the basic institutions of the economy (political, legal, informal, etc.), the development of these components does not give the expected results.

The classification of institutional elements proposed by Valieva is curious [16]. The study of institutions is carried out in the context of innovation. Valieva proposes to consider the following groups of institutions:

1. A macro level (a level determined by the "rules of the game"): laws and regulations; contract law; property rights; enforcement (a system of enforcement of contracts); sociocultural norms; institutional trust.

2. A micro level ("an institutional structure of production"): options market transactions (the costs of ex ante / ex post, conditions of uncertainty, frequency of transactions, asset specificity); alternative institutional arrangements for the effective exchange; market research, integrated structures and hybrid agreements (franchising, networking, long-term contracts); interpersonal trust.

This classification is a description of the institutional environment necessary for effective stimulating innovation.

The most complete set of institutions necessary for the development of economic systems is represented in the Polterovich "Transplantation of economic institutions" [17]. This set covers all areas of economic systems operating correctly, and it is, in our view, sufficient to describe the effect of the innovation environment for evolving SMEs on the development of the institutional component.

However, it should be added that the institutional framework of the innovative environment cannot be represented only by a set of necessary institutions, as it will not reflect the specifics of Russian realities.

\section{Materials and methods}

This assumption allowed forming the structural scheme of the institutional framework of the innovative environment. In this scheme, a basic institutional framework is represented by a set of specific institutions, which form the innovation environment of the region and have an impact on the activities of the innovation system actors. The proposed set of institutions is divided into two groups: those institutions that directly affect the development of innovative environment and institutions, whose influence is indirect, but also important.

In our opinion, the analysis of institutions as a part of innovative environment should be implemented considering the following factors:

a) subject-object relations within the environment, since the environment cannot exist independently from the subject, regardless of the environment;

b) the relationship "environment - system" when the environment under certain conditions is a system;

c) network relationships of the innovation system actors, which is a basic condition for providing the possibility of collective learning, sharing, cooperation, and finally obtaining of a synergistic effect.

Based on this consideration it seems appropriate to analyze institutions as a part of the environment within a regional innovation system, where the main participants 
are its actors with the relationships between them. These relations include the elements that implement the function of knowledge generation (research institutes, universities, industry science and others.), the elements realizing the function of the educating (universities and others.), infrastructure institutions which are intermediator, authorities acting as a regulator and, finally, key actors - small, medium and large businesses.

As a result, characterization of the efficiency of the institutions proposed a set of specific indicators to estimate the level of development of the innovation environment. The list of the indicators is a sample.

\section{Results and discussion}

The result of analysis of institutions development of Tomsk region and five more innovation-oriented areas of the Russian Federation is given in the article.

Analyses of the indicators reflecting the development of the institution of private property and personal security show the interesting picture.

The first indicator of Personal Security Institute is the OECD Better Life Index (Figure 1).

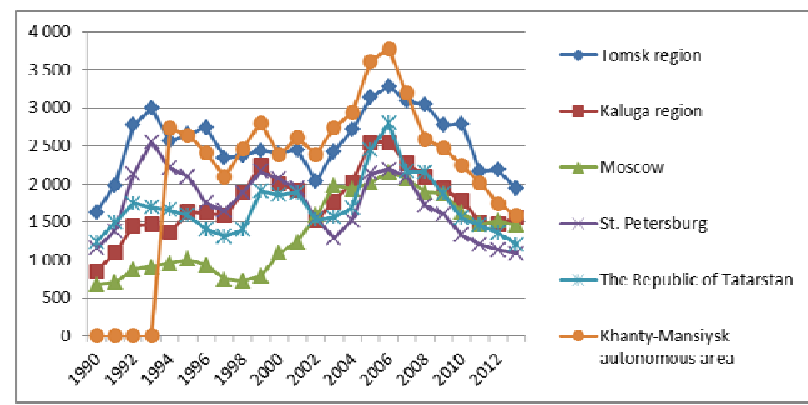

Fig. 1. The number of murders per 100000 inhabitants [18]

The index of Tomsk region compared to other subjects looks very advantageous, as it is much lower than others. But comparing with the total number of crimes, it is obvious that in Tomsk region there are many crimes of another nature.

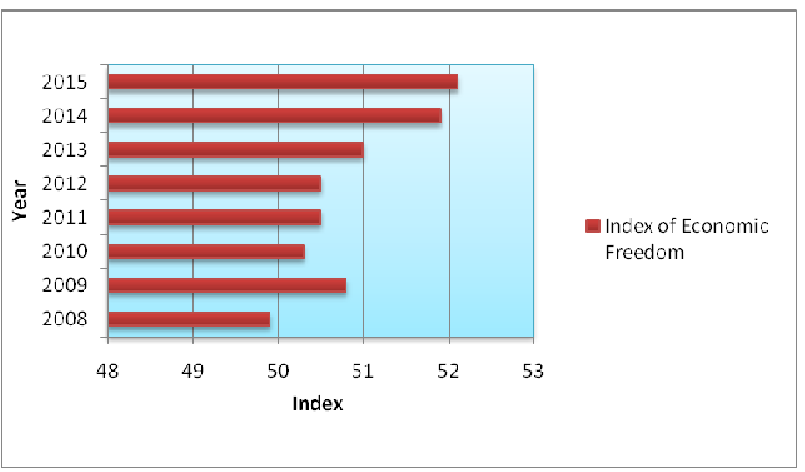

Fig. 2. Index of Economic Freedom (Russia) [18]

The second institute in this indicator is the institution of private property, which consists of such indexes as:

Index of Economic Freedom (Heritage foundation) (Fig. 2)
The number of recourses to law enforcement authorities in connection with raider capture of an enterprise (Figure 3).

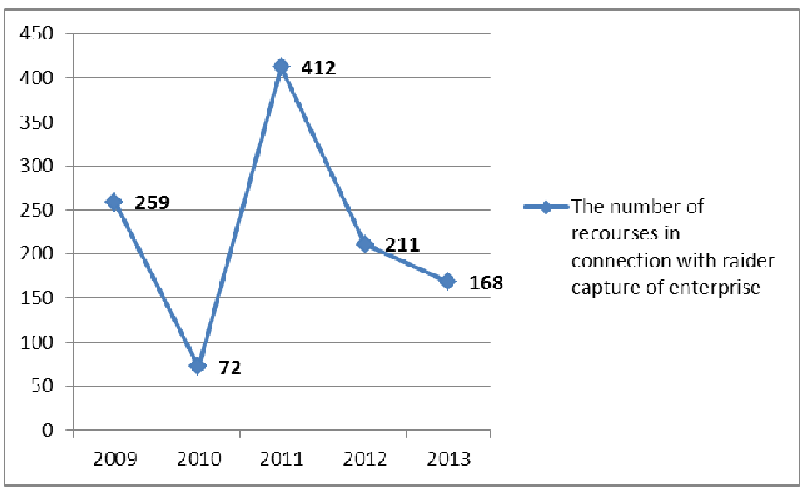

Fig. 3. The number of recourses to law enforcement authorities in connection with raider capture of an enterprise (Russia) [18]

Authors define economic freedom as "the lack of government interference or obstruction of production, distribution and consumption of goods and services, except for necessary protection of citizens and support of freedom itself'. Analysis of economic freedom has been carrying out annually since 1995 .

In summary, one can say that the Institution of Private Property is absolutely disastrous for the Russian Federation, since there is a large percentage of corruption.

The next institute is an institute of trust in region, which consists of three groups of indicators: the level of institutional trust, interpersonal trust and the level of state regulation of economy.

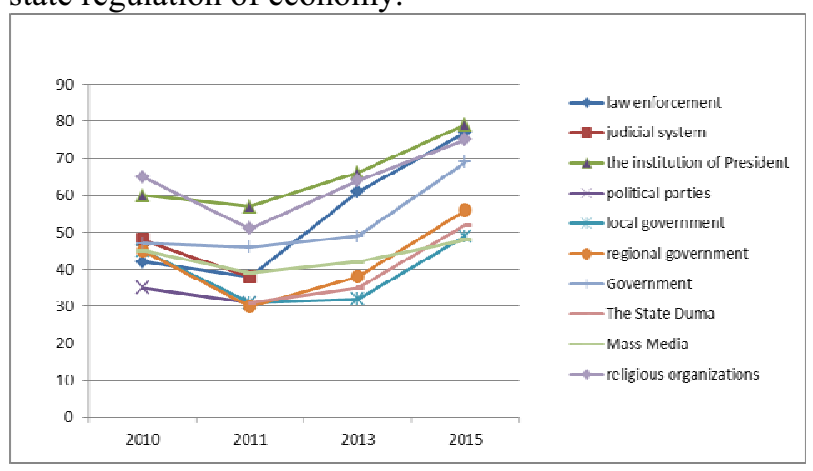

Fig. 4. The level of institutional trust (in percent)

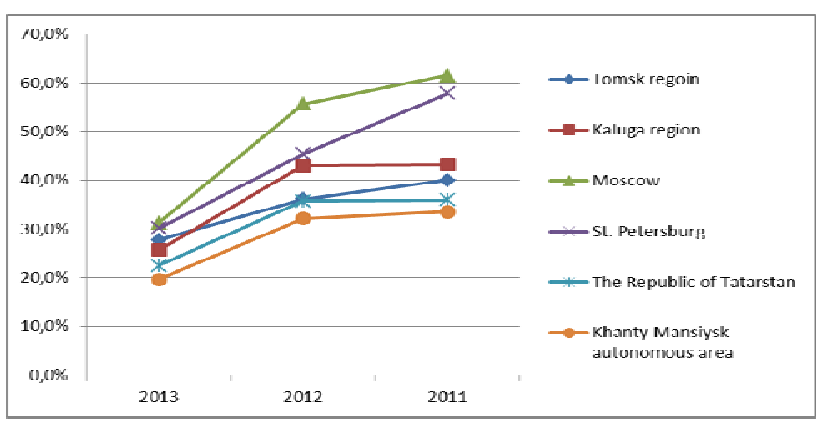

Fig. 5. The share of the public sector in business and industry [18] 


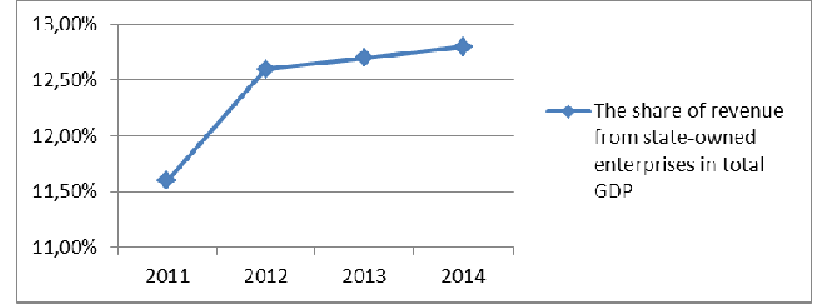

Fig. 6. The share of revenue from state-owned enterprises in total GDP [18]

The level of institutional trust in Russian Federation is quite low. According to a survey of Public Opinion Foundation, trust to the all politician institutions is extremely low, except the institution of President due to charismatic influence of the leader of the country.

The next group of institute is an Institution of public control. The level of public control is a key prerequisite (as experience of development of economically advanced countries shows) for the creating of successful economy with trends of sustainable growth.

An assessment of this institution is carried out with the help of the following indicators:

- whether there is or there is no regional act on public control.

- the number of independent social organizations in regions, which provide consumer rights protection; protection from discrimination; tolerant relations in society; protection of vulnerable population groups (single mothers, persons with disabilities, orphans etc.); (Figure 7)

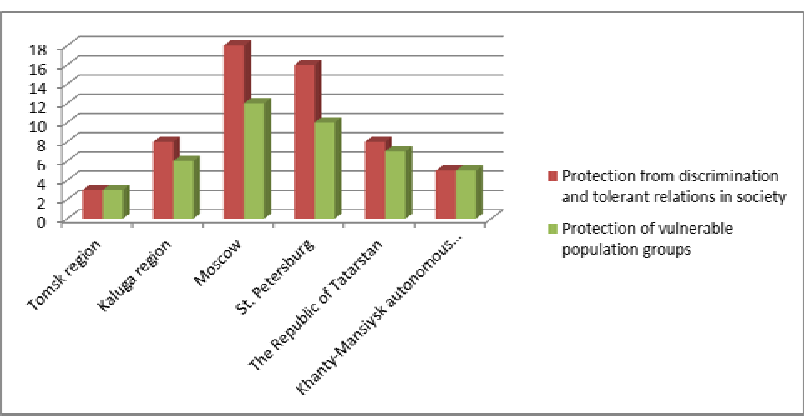

Fig. 7. The number of independent organizations that protect human rights in region [18]

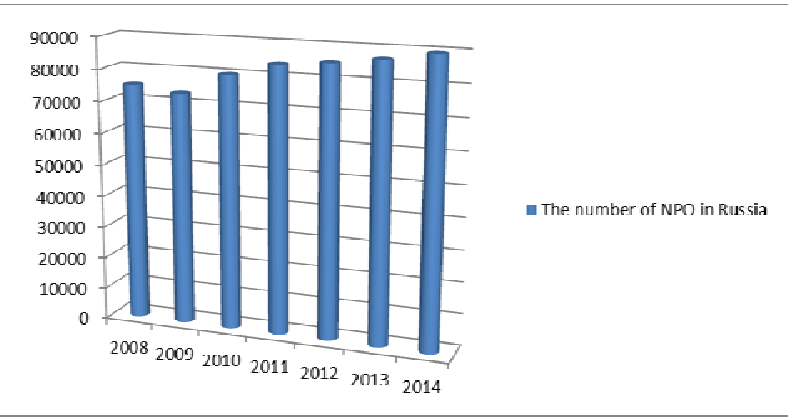

Fig. 8. The number of NPO in Russia

In every region there are different types of protective organizations, the difference is that in some regions one organization works with all types of discrimination, while there are a lot of profile organizations in other regions. In every region there are different types of protective organizations, the difference is that in some regions one organization works with all types of discrimination, while there are a lot of profile organizations in other regions.

In Russia NPO almost do not cooperate with business, while in developed countries the impact of NPO on business is very high. According to many experts, in Russia, where governance in social sphere is not very effective, an alliance of business and NPO will help to solve many problems at less cost.

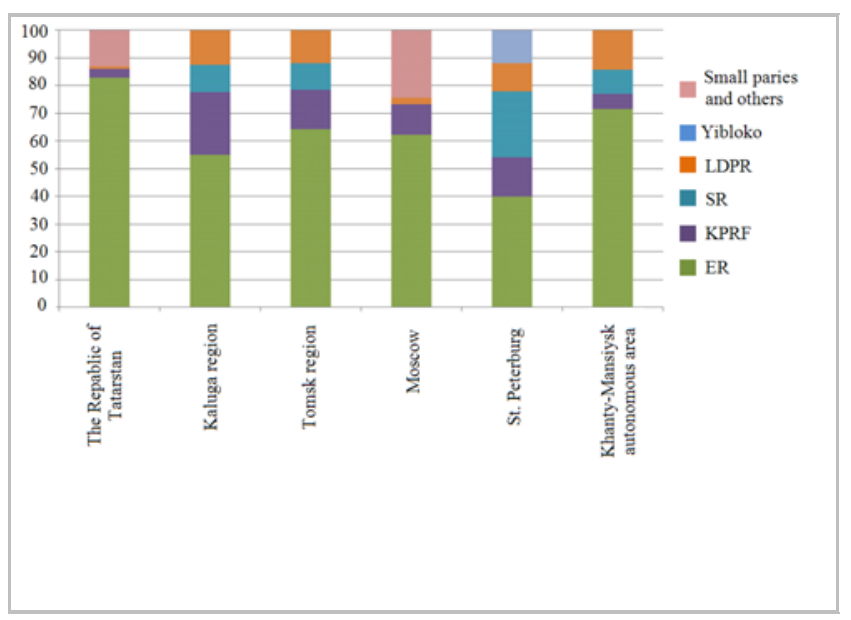

Fig.9. The number of parliamentary parties represented in the regional Parliament

It is clear, that in all regions except for St. Petersburg there are more representatives of the main political party (Edinaya Rossiya) than those of other parties. This situation says that in regions in the sphere of parliamentary decisions public control tends to be minimum.

The number of open areas (including Internet portals) to express public opinion about bills in subjects of the Russian Federation is shown by an indicator characterizing the partnership between the state and society.

There is at least one Internet area to discuss region laws in every region.

The last indicator of this group is an indicator characterizing civil representation in the state structures.

The first index is the presence of the regional office of the Public chamber of the Russian Federation.

The second index is the presence of NPO that functions in the region and observes elections. Currently in Russia there are 4 non-profit organizations, which observe elections (the branches of these organizations are available in all regions).

The third index is the presence of ability and forms of public participation in hearings of the local legislative bodies, reports of the Governor, feedbacks from the Governor.

After analysis of all evaluation indicators of the Institute of public control, one can say that this Institute 
works poorly and public control in many cases exists only de jure.

And last but not least - there are Institutes of Fiscal Federalism, of Local Governance, for Social Policy, of taxation and the lending Institution.

Let us start with the Institute of Fiscal Federalism. It is suggested to use the following indexes for its evaluation:

- The specific weight of regional and local taxes in the budget of the Russian Federation

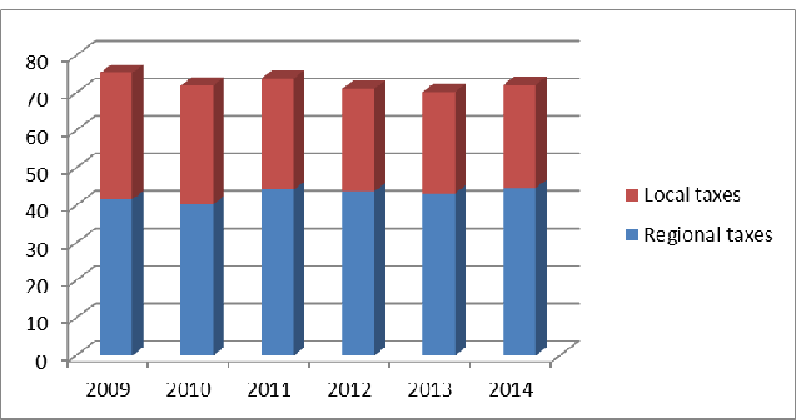

Fig. 10. The specific weight of regional and local taxes in the budget of the Russian Federation (in percent) [18]

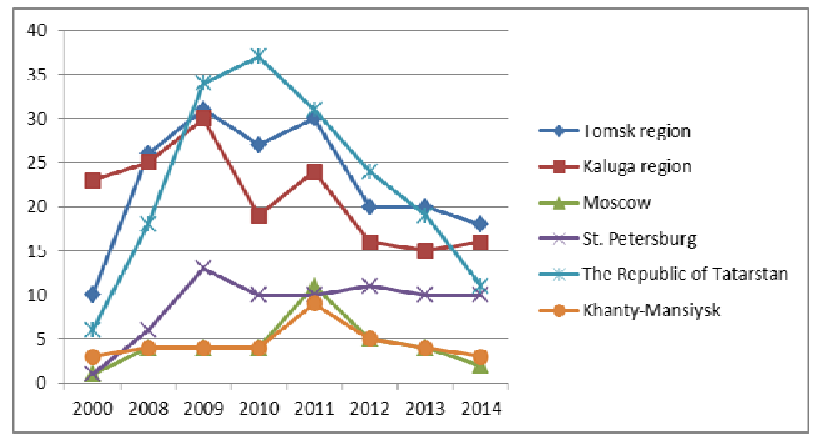

Fig. 11. The percentage of transfers from local budget of the region (in percent) [18]

Analyses show that from year to year there is about the same ratio of local and regional taxes in Russia (about $40 \%$ of regional taxes and about $30 \%$ of local taxes). The presence of the alignment system through transfers from the Federal budget, and the size of transfer from the Federal budget (Fig. 11).

Decentralization allowed the regions of the Russian Federation to form their budgets on their own way. The regions with the same volume of the budget distribute them among the main items of expenditure in different ways.

The next institute is the Institute of Local Governance.

The first group of indexes is the number and types of local taxes.

The second group of indexes characterizes the ability of the local government to solve organizational, financial problems regarding construction of infrastructure in the region.

The third group of indexes characterizes the presence of elected authorities of the regional and local levels
(Yes/no). Currently in the regions of the Russian Federation there are elections of authorities of the regional and local levels, which show the openness of the election of officers.

The next institution that we consider is the Institute of taxes.

In all regions there are laws allowing the use of tax benefits for SME and innovative enterprises, this can be observed especially in regions where there are special economic zones SEZ (in our case all regions except Khanty-Mansiysk autonomous area have special economic zones (table 1)).

Table 1. The special economic zones in the regions of the Russian Federation and the number of residents.

\begin{tabular}{|c|c|c|}
\hline Region & $\begin{array}{c}\text { Date of the } \\
\text { occurrence }\end{array}$ & $\begin{array}{c}\text { The } \\
\text { number of } \\
\text { residents }\end{array}$ \\
\hline $\begin{array}{c}\text { The Republic of } \\
\text { Tatarstan }\end{array}$ & 21.12 .2005 & 42 \\
\hline Kaluga region & 28.12 .2012 & 1 \\
\hline Tomsk region & 22.07 .2005 & 61 \\
\hline St. Petersburg & 21.12 .2005 & 33 \\
\hline Moscow & 21.12 .2005 & 38 \\
\hline Moscow region & 21.12 .2005 & 90 \\
\hline
\end{tabular}

In accordance with these data in all regions, except forKhanty-Mansiysk autonomous area, there are SEZ and the more they work, the more residents they have and the more the volume of shipped products (Figure 12).

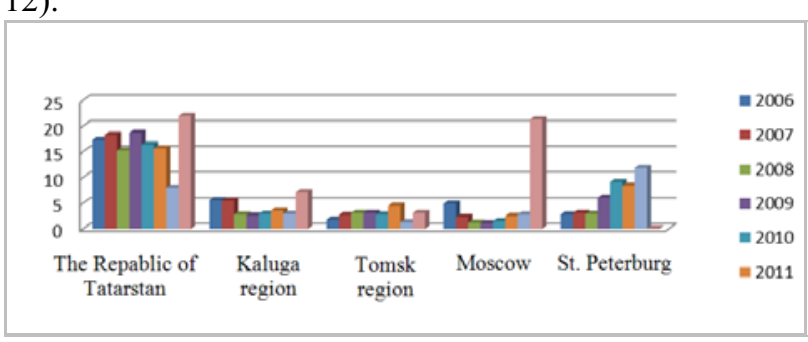

Fig. 12. The volume of shipped products of residents of SEZ in comparison to the volume of shipped products in the region [18]

And the last institute is the Lending Institute. The main goal is providing loans for enterprises and individuals. Currently there is a huge number of banks, that make loans, but the interest rates of loans are completely different depending on the loan term, the amount of annual profit of the company and other options.

After analysis of all evaluation indicators of the Institutes, one can come to the conclusion that some institutes in the Russian Federation are badly developed, some have a form of quasi-institute. There are many benefits and profitable terms de jure (in laws and programs), but even a half of them do not operated. There are taxes and credit benefits, but they are so insignificant that do not influence business much.

Also in Russia there is a high level of corruption that prevents development of these institutes. Accordingly, if 
the corruption was less, there would be more trust to the government and to each other, more trust to the private property and personal security.

\section{Conclusion}

As a result, it is clear that some institutes are developing slowly, although de jure there are all conditions for their development. (Despite the fact that there is a strategy of innovative development of the Russian Federation, one of the priorities is stimulating innovative development at the regional level. This strategy should provide the development of the regional programs and strategies of innovative development with the involvement of the relevant scientific and educational organizations, enterprises and development institutions).

In fact in order to create such conditions there should be the will and the desire of the federal and local authorities. Besides, it requires an appropriate infrastructure, which works at the federal level and allows forming "Skolkovo" in every region, rather than a few separated infrastructure organizations throughout Russia. There is a lack of information infrastructure and new forms of innovation environment. There is no atmosphere that can inspire businesspersons to take risks in the process of innovation. The absence of business culture does not allow businesspersons to make decisions in favor of the starting and development of a business taking into account all risks.

\section{Acknowledgment}

The programme was realized and subsidized within the framework of the Programme for enhancing Tomsk Polytechnic University's competitiveness. The results presented herein were obtained with the assistance of the Russian Foundation.

\section{References}

1. T. Hobbs, Lev. Harm. (Pen. Books, 1968)

2. D. Hume, A Treatise of Human Nature (Oxf.: Clar. P., 1888)

3. H. Spencer, Facts and comments (Soc. Stat., 1851)

4. É. Durkheim, The Rules of Sociological Method (1895).

5. D. Pletnev, Vest. Chel. gos. un., 10, (2012)

6. G. Schmoller, Grundiss der Allegemeinen Volkswirtschaftslehre (Ber.: D. \& H., 1923)

7. A. Wagner, "Speech on the Social Question» (abridged), in D. O. Wagner, ed. Soc. Ref.. (N.-Y., Mac., 1939)

8. T. Veblen, Quart. Jour. of Econ. (1898)

9. J. Commons, Institutional Economics: Its Place in Political Economy (N.Y.: McMil., 1934)

10. D. North, Institutional Change and Economic Performance (Cambr. Un. P., 1990)

11. O.E. Williamson, The New Institutional Economics: Taking Stock, Looking Ahead. J. of Ec. Lit. XXXVIII, (3), (2000)
12. A. Schotter, The Economic Theory of Social Institutions. Cambr. Un. P., (1981)

13. J. Knight Institutions and Social Conflict, Cambr. Un. P., (1992)

14. V. Matveenko, J. of Ins. Sc., №1 (2010)

15. I. Kolmakova, T. Shindina, № 1 (2012), [Electronic resource] www.science-education.ru/101-5602

16. O. Valiieva, Ves. NGU, (2007)

17. V. Polterovich Transplantacia economicheskih institutov, Ec. n. sov. R., №3 (2001)

18. Federal state statistics service [Electronic resource]/ www. gks.ru

19. N. Chistyakova, T. Gromova, V. Spitsin, ERMM, (2015) 